\title{
AGUA, VIENTO, FUEGO Y TIERRA EN EL ROMANCERO ESPAÑOL POR
}

\section{CLEMENTINA DIAZ Y DE OVANDO}

T OS sistemas religiosos, llevados de su afán de explicarse lo incognosciL ble, así como las especulaciones filosb́ficas, se adentraron desde antaño en el estudio del complejo origen vital.

A los cuatro elementos los filósofos griegos atribuyeron la creación de la vida y discutieron arduamente sobre la primacía potencialmente creadora de cada uno de ellos; opiniones que, concretadas por Aristóteles, influenciaron todo el pensamiento religioso y filos6fico-cientifico del hombre medieval.

San Basilio considera a la tierra como la promotora primaria de la vida y San Agustín aduna a sus ingentes preocupaciones teológicas, la preocupación por el tan debatido problema siguiendo asimismo la doctrina aristotélica.

¿Es en este sentido escolástico como se proyectan los cuatro elementos en el Romancero? 
Poesía impregnada aún de Edad Media; pero surgida de la brega cotidiana con la morisma, el concepto aristotélico pasa inadvertido, y no porque el romance eluda los asuntos filosóficos, sino por serle más preciso narrar los acontecimientos heroicos, acordes a su esencia noticiera.

Alguna vez, sí, la tierra, como germen vital y también corno término aparece en sus temas: tal aquel romance artístico El Cautivo:

Tomando un puño de tierka
lo beso $y$ mojo con agua,
diciendo: Fin y principio
de la composturz humana
de ti pacen mil deseos
y en ti finalmente paran ...

De igual manera pasa inadvertida la función biológica de los elementos; únicamente el agua es reconocida por el romance como necesaria a la vida. En el Cerco de Zamora, una vez consumada la traición de Vellido Delfos, Diego Ordóñez en su desmedida cólera reta no sólo a los zamoranos :

al traidor Arias Gonzalo

y a todos los zamoranos

puea en ella se han ballado;

sino también a las dos fuentes nutricias del pueblo:

y a los panes y a las aguas. . .

$Y$ la coridesa, esposa del conde don Grimaltos al llegar a una fuente:

Dió gracias a Dios del cielo que la trujo en tal lugar, diciendo: i Buen agua es esta park quien tuviege pan 1

Cuando las hijas del Cid Campeador, vejadas y abandonadas por los pérfidos Infantes de Carrión, encuentran a un pastor a quien demandan socorro, deséanle que el agua nunca falte a su ganado:

Por Dion te rogamos, home, que now bayas compasión, atí tus ganados vayan siempre de bien en mejor: nunca les falten las aguas en el extio $y$ calor. . 
Delgadina, condenada a morir de sed por su padre:

que se muera de sed de agua. $\therefore$

comprende que es la falta de ella causa de su muerte:

que de sed $y$ no de hambre

al Dios vo a dar el alma...

De los diversos pueblos invasores de la Península y que en la mente llevaban sus interpretaciones miticas sobre los cuatro elementos, el Romancero alude las concepciones hebraicas y muslimes.

El romance, no soslaya la adoración del agua y del fuego en las culturas clásicas; sólo un frío romance erudito describe la raíz telúrica al estilo renacentista :

\section{Dando la preñada tierra muestras del bien que abscondia $y$ ofrece abundante frato y primavera cumplida. $\therefore$}

La mitologia gotónica, que concibe a Nertus, la tierra, como signo de fertilidad, y at agua, al viento y al fuego como los destructores elementos que secundaráti a los hijos de Muspell para destruir a los Ases y a la vida cuando la profecia de Völuspa se cumpla, tampoco interesan al romance; algunos presagios -el águila que arroja fuego de los romances carolingios--, acusan un dejo germánico. Lo clásico y lo visigótico son ya distantes a la creación del romance, no asi lo arábigo y lo hebraico, pueblos ambos con los que el español convive.

La tierra, material con que se plasma al hombre en la religión hebrea, octurre en el romance:

\footnotetext{
Vuélvete para tu casa.

villano y de mala tierra...
}

dice a don Juan la calavera.

La designación sacra del agua que aparece ya en los principios de la lírica en el Debate del agua y del vino (siglo xIII) y en el cial el agua aduce como razón incontestable ser ella quien cristianiza, no existe en el romance. En cambio, el agua del Jordán, río bíblico, tiene poder milagroso en el romance titulado El Baño en el Jordén: 


\begin{abstract}
A wuelta de nu cabezz. caido lo vido estar. allá te le fué, a way dentro del río Jordín: como fué deatro caído sano le vió levantar.
\end{abstract}

En cuanto al fuego expiatorio de que habla la religión católica, el romance no lo menciona como tal; si eventualmente lo inserta, es para relacionarlo con el dolor de una candente protesta:

Canndo parta ixt dexecho

a la celeatial morada,

pues me hi sido purigatónio

at fuego de tur palabras. . .

o con la ansiedad de amor:
arrojando unos suspiros
del infierno de sus ansias
que mis sospechas enciepden
y mis contentos abrasan...

La pasión árabe por el agua, que esparce frescura en el Alhambra y que avalora la belleza del Darro $y$ del Genil, se trasluce en los romances fronterizos "hechós por cristianos al modo árabe" y en los moriscos. El mayor elogio que recibe la ciudad agarena es :
Alora, la bien cercida
tú que eutis en par del ríb...

$Y$ el no ver al Genil, es el castigo que por su crueldad desea el amador a su dama :

$$
\begin{aligned}
& \text { I.Y cuando dejes las aguas } \\
& \text { de Genil fértil y claro. } \\
& \text { y vayas a las riberas } \\
& \text { del turbio y corriente Tajo } \\
& \text { donde no hay Abencerrajes. . . }
\end{aligned}
$$

"Moro viejo" at predecir in victoria del Cid sobre Valencia, anuncia la: mayor desgracia :

tu ria tan coudaloso
to rio Guadalquitif,
con las otras aguas tuyas 


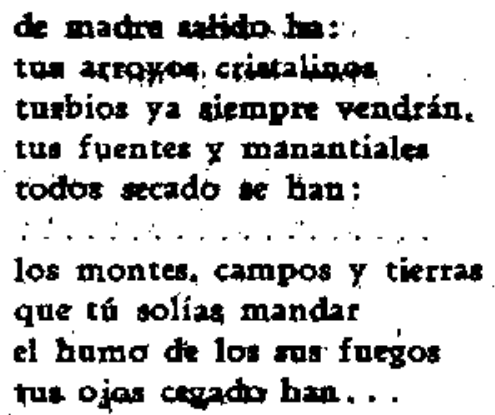

Mientras Fernando el. Católico, amaga con sus huestes a Granadá, el rey Chico goza del agua y del viento:

$$
\begin{aligned}
& \text { estando en Genetalife } \\
& \text { una muy frectanana } \\
& \text { gozando del fresco viento } \\
& \text { y viendo correr el agua. . }
\end{aligned}
$$

El Romancero, a pesar de su reseña incidental de los elementos en su aspecto filosófico, biológico y religioso, dirige principalmente sus apreciaciones hacia dos rumbos bien definidos: uno subjetivo -exposición de los elementos en el sentimiento-; atro objetivo - la guerra- en el cual, éstos actúan como factores decisivos en el desenvolvimiento histórico español.

Procuraremos analizar estos dos aspectos: primero el sentimental; después el histórico.

\section{EL AMOR, EL PAISAJE Y EOS ELEMENTOS}

Si aquellos sabios y profundos filósofos de ta Antigüedad y de la Edad Media, no lograron deterninar al elemento preponderante en el origen de la vida, el juglar lo logra cuando declara al fuego emblema del sentimiento amoroso, sin preocuparse, desde luego, de su esencia y propiedades que harán pensar a Descartes " $\mathrm{el}$ fuego que arđe en nuestros corazones es de la misma naturaleza que el que quema los cuerpos inanimados?", cuestión que nunca se plantea el poeta romancista ni tampoco otros autores. Fernando de Rojas, maestro en el arte amatorio, considera también al fuego consubstancial al amor, y parangona no su natuyaleza, simo su in- 
tensidad, con el que consume a las ciudades. En la Tragicomedia de Calisto y Melibea; Calisto, después de haber escuchado la canción, según él más triste: el romance Mira Nero de Tarpeya - a Roma como se ardía..., afirma que stu fuego es aún más intenso; afírmación que provoca el asombro de su criado Sempronio, que le pide elucide ese misterio:

"Sempronio.-Digo que ¿cómo puede ser mayor el fuego que atormenta a un vivo, que el que quemó tal ciudad y tanta multitud de gente?

"Calisto._- Cómo? Yo te lo diré. Mayor es la llama que dura ochenta años, que la que en un día pasa, y mayor la que mata un ánima, que la que quema cien mil cuerpos. Como de la apariencia a la existencia, como de lo vivo a lo pintado, como de la sombra a lo real, tanta diferencia hay del fuego, que dices, al que me quema. Por cierto, si el del purgatorio es tal, más querría que mi espiritu fuese con los brutos, que por medio de aquél ir a la gloria de santos."

El fuego que emerge del tremedal de la pasión lo reitera el Romancero.

En los romances del Conde Claros y Claraniña, o del mismo conde y Galanzuca, que recuerdan los amores de Emma, la hija de Carlomagno y su paje Eginardo, conde Claros sufre los efectos del fuego e impreca por ello a Eros y a su madre Venus:

$$
\begin{aligned}
& \text { ¿Ob' maldito seas Cupido! } \\
& \text { iY Venus otro que tal } \\
& \text { porque así mo habtis metido } \\
& \text { en este fuego infernal! . . }
\end{aligned}
$$

El fuego anímico que lo consume irradia en su vestuario:

$$
\begin{aligned}
& \text { Y unos zapatos franceses } \\
& \text { de un carmeai singular. } \\
& \text { con unau lenguas de fuego, } \\
& \text { relumbran como cristal; } \\
& \text { el mote que tiene escrito } \\
& \text { es este que oiréis nombrax: } \\
& \text { "Aunque arden de contino } \\
& \text { co se acaban de quemar"... }
\end{aligned}
$$

y la ausencia para otra amante se convierte en fuego:

$$
\begin{aligned}
& \text { porque en apartaree de al } \\
& \text { en vivo fuego se abriea... }
\end{aligned}
$$

además no admite tardanza el fuego de amor: 


\section{Límplatine in jwerina; ve presto: no tardes paje. que para el fuego que terigo muy pronto sers tarte...}

y fuego son los desdenes:
Abrasado en viva llama, bravo, feroz y rebelde, porque estraba hecha de yelo la que tanto fuego enciende...

y el fuego del querer no se apaga:
y con eato el Bencerraje aplacó su ardiente llama; pero no mitígó el fuego que tu corazón le abrasa...

El agua no es ajena al mal de amor: sale del pecho y se muestra en lágrimas acíbares; la índole del llanto como expansión emocional, la explica clara y sentidamente el romance morisco de Abenámar:
no te espantes que mis ojos
ante ti derramen agia.
porque al fin los ojos son
las alquitaras del alma. por donde el amor destila los vaporea que derrama
la pena en el corazón
con el fuego que le abrata, cutyo valor exceisivo

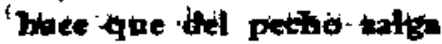 ef igo, con que tolot del corazód te deacaxys: y como a mi me combaten fuego, amor, temor, mudaszo, celos y sorpechas Horo, porque el corazon descanasa... id

y llora el desgraciado pastorcillo:
Aquel moate artiba $\nabla a$
un pastoxillo ltorando:
de tanto como lloraba
el gabán lleva mojndo... 
y también el famoso y fiel amador Amadís de Gaula :

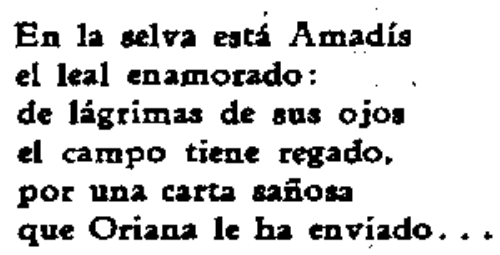

En el romance de Don Tristín y la reina Iseo, el agua es milagrera y culpable de un desliz amoroso:

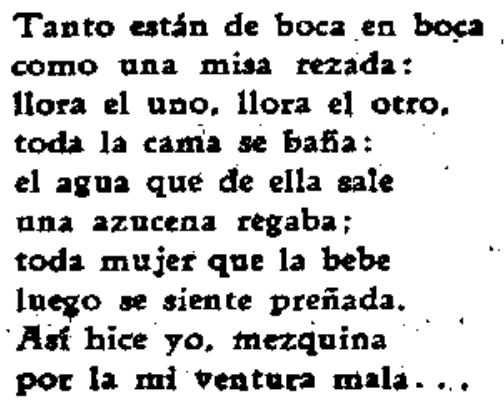

La inestabilidad espiritual de la amada es comparable al viento:

iOh mis mudable que el pientọ! ...

y mensajero, es también, de la dolencia amorosa:

I deja que el viepto lleve

ous quejas $y$ sius palabras. . .

Sin duda, el más desdichado entre los amadores romancescos, fué el Rey don Rodrigo, ya que por su desastrada perturbación perdió el reino. El Rey, en la descripción de ou penar, evoca a los efectos 'naturales en el bello y exquisito romance Rodrigo y la Cava:

De cuatro elementos

los trea combaten conmigo:

el fuego est en mi pecho.

el aire está en mis suspiros.

toda el agua está en mis' ojos.

autores de mi castigo,

quedíndome oblo el cuarto,

que es en tietre convertido,

pues una dichosa muerte

vence todos enemigos... 
Igualmente en el fondo sensorial de: los amantes que escarnecen al Veinticuatro de Córdoba, batallan los elementos:

De todos enatro elementos
son con fuerza combatidos.
De una parte el agua y viento
dan lágrimas y anspiros
por otra la tierra triste,
que los tiene divididos.
y el fuego que por encima
de sus almas se ba encendido,...

Recordemos aquí la rima del gran poeta sevillano Gustavo Adolfo Bécquer :

Los suspiros son aire, $y$ van al aixe.

Las lágrimas son agua, y van al mar.

Dime mujer: cuando el amor olvida.

¿Sabes tú a dónde va?

Y citemos asimismo el soneto Anhelos, de don Francisco Rodriguez Marín, en el que aún persisten los elementos en lo sentimental.

El agua y el fuego intrínsecos al amor, se tornan en determinadas ocasiones en su castigo:

Mandólá prender so padre,

$y$ meter en escuridad.

el agua hasta 12 cinta...

El fuego amatorio de Conde.Claros, es sanción de Galanzuca, su amada :

Tate, tate, dijo, fraile. que a mi nunca Degarás

que nunca llego a mi hombre

que fuese vito en carrie

ino aquel dox Clazas.

don Claros de Montalvan.

que por mis grandes pecados

por él me quieren quemar...

Don Claros no se conduele de ella :

Tanto me da que la queme nin 1a dejen de quemar: que mujeres en el mundo 
pare the we hen de falturn

Si no lo tienes de guapas,

lo tendrán de habilidad.

y al oír las palabras del conde, el rey manda preparar la hoguera:

Siete criados, tenia.

leña lea mandó apañar

para quemar Galanzica

bija del rey tan gália...

El romance, complacierite siempre con los desvios amorosos, no permite semejante pena por tan fütil motivo:

que los yerros por amores

dignos son de perdonar...

y conde Claros acude por fin a salvarla:
Ahora con esi bifa
con ella quemar un can.
Ei quemindo bien 108 butiot.
al tét idlow presentat:
que Galanzuca es mi esposz
y yo la voy a llevar.
- Lévela el don Claros, lleve,
Dios te la deje lograr:
mas quiero que se la lleve
que non vecla aqui quemart .

La infanta doña Urraca también merece ser quemada, pues en su despecho por no haber obtenido herencia, pretende amores ilicitos con moros Y cristianos, tal dice en el tomince: ' $Q$ inejos de dono Urrace, su padre el rey Fernando:
Calledes, bija, calledes, no digades tal palabra.
que mujer que tal decía
merecía ser quemada...

El agua y el fuego son análogo cillicio de adúlteras; el romance recoge la costumbre de quemarlas vivas o arrojarlas al màr : *

* Costumbre variable según los paísea y los tiempos. En Francia, encerradas en una jaula eran arrojadas al agua. en Inglaterra oe les introducia en la jaula junto con un gato. y en Alemania en la regocijada comedia El hierro caliente de Hans Sachs tenian que tocat este candente hierro que to les producia quemadura alguna. si se encon-

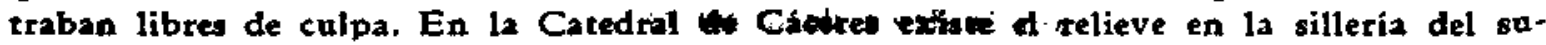
plicio de unas adúlteras, como pateste necuerto dal castigo. 
qu mujex que don aniese

en un parto $x$ en an día.

que la den por aleyosa.

y 12 quemen por justicia,

o la echen a la mar

porque adalowrader mabita. .

La emperatrix de Alemania acusada por I

que nosotros hemos visto

a la emperatriz un día

holgar con su camarefo,

no mirando que haçia

traición a ti gran exñor.

y a su gran genienlogía.

es condenada al fuego:

$$
\begin{aligned}
& \text { que el emperadoc tenia } \\
& \text { para dar la gran centencia } \\
& \text { de chemar la emparmia. . }
\end{aligned}
$$

Los elementos, que han sido en los romances valores emotivos o sanciones para el impetuoso querer a no participan én el paisaje de las escenas amorosas que nos refiere el Romancero?

El primitivo romance raras veces desvía su actitud precisa del tema amoroso o heroico, para fijarse en los detalles accesorios de la acción; alguna que otra vez, el paisaje se visłumbra en ellos, intensificándose al parecer en los moriscos:

\section{Al tiempo que el sol exconde debajo del mar su lumbre $y$ de roion atreboles colora el aim y. lat aubet...}

No obstante, la presencia del paisaje en las obras anteriores, la visión del paisaje empieza a seducir y a agudizarse con el advenimiento del Romanticismo. Azorin, en su estudio El paisaje de España visto por los españoles, afirma lo anterior y concluye : que el gusto consciente de la Naturaleza dimana de lo romántico, juicio quẹt desđe luego, podemos proyectar en el romance.

Con la terdencia romintion, los elementos son decoración imprescindible del paisaje escenografico, adecuado a $\mathbf{l a}$ personalidad det autor o del protagonista, confundiéndose con su ánimo, ya alegre, ya sombrio. Es en los romances del prerromántico Juan Meléndez Valdés, donde además 
de advertirse ya una sugerente sensación de paisaje, los elementos intervienen en función del desarrolio dramático, para adquirir plenitud definitiva en los romances del duque de Rivas.

Sin embargo, esto no es novedoso. Ya los romances $A$ viso de la fortuna y derrota de Don Rodrigo (el más viejo de los romances tradicionales del ciclo de este rey, compuestos de 1450 a 1510, según don Ramón Menéndez Pidal), y el romance Del Rey don Judin que perdio a Navarra, lo denuncian :

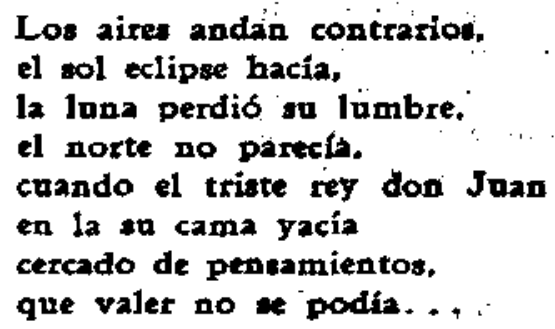

En estos dos romances los elementos son también causales y compañeros de desgracias, anticipándose de este modo a los recursos dramáticos del Romanticismo; y nos demuestran su esencia notoriamente romántica y su infiuencia en el espíritu de este movimiento.

Para Meléndez Valdés el fuego es pretexto para primorosa comparación con el sol:

Simil a un globo de fuego
que en vivas centellas atde...

el agua alegra el paisaje campestre y es elemento fecundante:

Bien vengáis, alegree aguts.

fausto alivio del tobarde

labrador. que ya temía

malogrados sua afanes.

Las que al tio undosis cotren.

agitando sus criatales

en sueltos círculos turbati

de los árboles la' itriagen...

Y en el romance de Doña Eleira, el viento farioso es considerado por la dama como agorero complemento de su angustia:

En guerra horrible combaten embravecidos los vientos, 
llenando an agudo silbo

de pavor mi helado seno...

En el romance El Sombrero del duque de Rivas, es ostensible la relación del escenario y los elementos; el viento y el agua van cambiando gradualmente su efecto teatral hasta llegar al climax trágico, Rosalia la protagonista, espera por la tarde a orillas del mar a su amado, que vendrá en su busca:
Entando el viento adormido.
la max blanquecina en calma,
y sin turbar el silencio
de las voladoras auras.

la noche la sorprende en vigilante espera:

Eptró la noche y con ella

despertíndose fué el viento

y el mat empezó a moyexes

con na mugidor estruendo.

y en el momento culminante el agua en grandes olas:

Se combaten, crecen, corren

para tragarse la tietra,

ya los abismos descubren,

ya las nubes se revientan.

Una salobre montaña.

que 1a playa arriba entza.

y rapida retrocede.

no dejando nada de ella...

Después del Romanticismo, el romance vuelve hacia otra renovación con Federico García Lorca. El poeta granadino reviste a su romance del rico atuendo metafórico; y el agua, el viento, el fuego y la tierra transmutan su función vịtal, heroica y ornamental en plástica función de belleza. El aire es el solícito guardián de la luna:

El aire, 14 vela vela

el aire la eaté velando...

áurea es el agua:

cortó limones redondos,

y los fué titando al agua

harta que la puso de oro... 
y el viento roba el verde color a las gitanos:

Verde que te quiero verde

verde viento verdes romas...

e "invisible enamorado" - Como lo llamara Dlaz Plaja-, persigue por el sendero a Preciosa:
Al verla se ha levantado
el viento que nunca duerme
¡Preciosa, cotre. Precioal I
que te coge el yieato verde!
¡Preciosa, corré, Preciowal
¿Míralo por dónde viene?
1 Sátiro de eatrellas bajas
con sus lenguas relucientes. .

Son también el aire $y$ el agua blasones de Granada:

$$
\begin{aligned}
& \text { por el agaa de Granade } \\
& \text { solo remen los sopiros. . }
\end{aligned}
$$

ciudad de pena y de llanto "que se hace presente por el agria y queda melancólicamente suspendida entre el cielo y la tierra".

\section{PRESENCIA DE LOS ELEMENTOS EN LO HISTORICO}

Pueblo, el español, permanentemente invadido. En los romances -interpretación de los hechos heroicos-, lejanos unos, actuales otros, siempre presentes, los cuatro cósmicos elementos deben representarse en íntima relación con los sucesos históricos, ayudando a los aborigenes a vencer al invasor, o conjurándose en su contra en las horas angustiosas de la lucha.

El viejo romance, el nuevo romance, el romance popular y el romance erudito, atribuyen a los elementos victorias y derrotas.

La tierra, en estos romances, no es elemento fecundo, es la extensión que se puede recorrer:

Irvos heis de tietra en tierra...

es el suelo:

hinquedea 12 lanes on tierna... 
Dero fundamentalmanten es el bien comuapl que ha sido arrebatado:

$$
\begin{aligned}
& \text { por culpa del pecado } \\
& \text { que comitid el rey hodmigo. } \\
& \text { el rey malaventurado. } \\
& \text { cuando perdieron los godos } \\
& \text { la tierra que habian gamado... }
\end{aligned}
$$

tierra perdida que es inaplazable reconquistar:

$$
\begin{aligned}
& \text { que nos libere las tietras } \\
& \gamma \text { que nos torne la paz... }
\end{aligned}
$$

Es moneda con la cual el Cid adquiere implementos bélicos; empeñando cofres llenos de arena a los judios don Raquel y don Vidas;

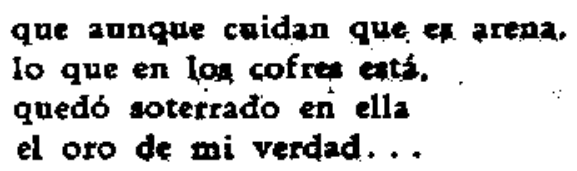

Es la disputa por la tierra, origen de la epopeya, del romance, del entusiasmo a los héroes, y permite la creación de. las instituciones democráticas de Castilla, por las que puede, un simple infanzón, increpar al rey:

"te ha ganado el Cid más tierras

"que te dejó el rey Fernando...

El fuego prevalece sobre el agua, el viento y la tierra como símbolo guerrero:
Al arma, al arma, anaban,
lo pifanos $y$ tomborea:
"Guerra, fuego, sangre" dicen
sus espantosos clamores...

Ya.los iberos, en su tenay resistencia a las legiones romanas son ayudados por el fuego; incendiada Numancia por Cipión, todos sucumben y al general no le es dable jactarse del triunfo:

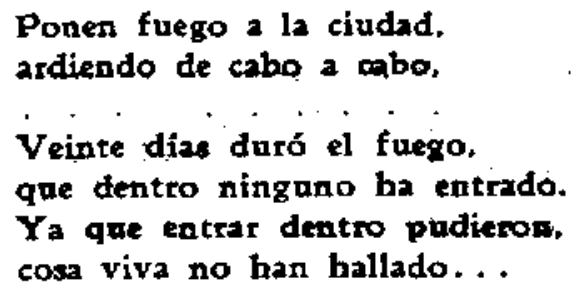


Fuego, agua salobre y viento marind, combinados armoniosamente derrotan al último rey visigodo, que no ha tenido la precaución de echar un cerrojo más, a la malhadada Casa de Hércules. El fuego es, el primero de los siniestros presagios:

Rey has sido por th mat:

que el rey que esta casa abriere

a España tiene quemar.

Vino an águila del cielo

la casa fuera a quemar...

La Cava Florinda, lamentándose de sú fatal belleza, al ígneo elemento la equipara:

tú erés perditión de Espafia

fuego que tódó ló apuira...

$Y$ el aire, pasivo en los suspiros del enamorado rey, al iniciar su terrible movimiento, es prenuncio desdichado:
Los vientos eran contrarios.
Ia Tuna estaba crecida.
los peces daban gemidos
por el mal tiempo que hacia.
cuando el rey don Rodrigo
junto la Cava dormia...

El agua huidiza de los ríos y el agua animada de los mares, desempeñan papel importante en la Historia, al decir del romance. En los viejos ríos hispanos, la vida se enriquece continuamente en emociones heroicas y el trovero romancista los considera centros vitales en las gestas.

De las aguas del Duero, espejos de imágenes bélicas, desde el tiempo de Fernando I, Antonio Machado se pregunta si su influencia abarca a todo el Romancero:

¿Y el viejo romancero

fué el sueño de un juglar junto a tu orilla?

El Tajo "hondo y amarillento" discurre con rumores épicos, sus aguas tiemplan los aceros necesarios a la defensa; y no permanece indolente a los acontecimientos trascendentes; cuando Vamba entra a Toledo para coronarse rey, el romance cuenta cómo el pueblo vitorea al elegido y lo que el río opina: 


\section{Y el Tajo les retponde manso y Iedo \\ unas veces Espana y otras Toledo...}

El río Guadalete atestigua el éxito de los sarracenos sobre el ardoroso rey :

$$
\begin{aligned}
& \text { Junto al río Guadalete. } \\
& \text { que a Jerez era cercano, } \\
& \text { aqueste rey don Rodrigo } \\
& \text { vencido queda en cl campo. } \\
& \text { Venciblo el moro : Earif : } \\
& \text { por el su triste pecado... }
\end{aligned}
$$

En el río de Carrión, Castilla empleza ourgir y a definirse como la directriz de la Reconquista, imponiéndose a los restantes reinos cristianos; el rey de León, al querellarse con Fernán González y recibir el acuoso. insulto, pierde la supremacia del condado:

$$
\begin{aligned}
& \text { El conde con lozanía: } \\
& \text { su caballo arremetio } \\
& \text { con el aguz } y \text { el arena } \\
& \text { al buen tey engalpico. }
\end{aligned}
$$

$Y$, đurante el quehacer libertario que canta la: epopeya, el héroe nace y crece junto al río Ubierna, y al abandonar Burgos, el río Arlanzón es límite de su amargura y Rubicón de su triunfo. $Y$ acaso el buen Cid, cansado de la aridez de la meseta:

Contra la mar salada-conpeçe de guerrear...

Es la contemplación del agua, la que hace grata a él y a su compaña la conquista valenciana, y allegados al mar, sus ojos de llana visión quedaron empapados de llanuras más ilímites aún, $y$ tal vez desde entonces, en la mente castellane quedó latente la domínación de las aguas oceánicas :

El arzobispo don Bernardo y la reina Constanza, enardecidos por las victorias cidianas, ganan la morisma el río Tajo:

$$
\begin{aligned}
& \text { Y ganó toda la Alcartia } \\
& \text { de la otra parte del río } \\
& \text { que agora Tajo al llama. . }
\end{aligned}
$$

Y en el ritmo heroico de la Reconquista al mando de Castilla :

Otros reyes sucedieron

$$
\text { que lo perdido' génaran. }
$$



pare al Quioto Furnando
que el cablico Jlamaras;
que con su esfuerzo gano
4 buea reino de Gramada...

En el Río Verde, los cristianos antes de la consumación total de la victoria sufren un revés:
I Rio-Verde, Rto-Verda mas negoo yas gue la tient?
Entre ti $y$ viers Bermeja murió gran caballeqia ....

Para el acianeno, ha llegedo el momento en que fuego, agua y viento se pongan en su contra, y el fuego de imocado para que diestruga la ciudad, antes que las huestes católicas penetren:
iOh Valencia, oh Valencia!
ide mal fuego wat quemada!
Primero fuiste de moros
que de cristianos ganada...

El muslímico deseo se cumple en Granada :

May revelta Granada

on armaa I fuego ardiendo...

$Y$ por el agua de un rio, el postrer rey de los moros huye:

Por ese Genil abajo $e 1$ rit Chien se alf́a. pas6 por medio del agua. 10 que hacer no solia...

Por el agua llegaron, por el agua partieron; el Mar de España, ha dicho Ricardo Rojas, es puerta de invasiones - y de evasiones; padowos agregar. El deseo de evadirse por el agua, lo piensa llewar a cabo Alfonso X, el Rey Sabio; que por la mar quiere deambular en busca de aventuras, como consuelo a la tristeza que la rebelión de su hijo Sancho el Bravo le dejara:

\footnotetext{
baré una galana negra,

que denote mi pesar.

- ith gobiano ninguno

me porné en el alta mar.

navegando de contigo

por las ventarim buscar....
} 
Fiste enhelo de aventuras lo posee Castilla en el siglo xv, que con la sumisión del moro y del cristiano no encuentra cauce a su enorme energla conquistadora; y cuya nostalgia por el agua:

\author{
¿Castifla. España de largos rios \\ que el mar no ba visto y corre hacia los mares...
}

que el poeta de hogaño renueva bellamente, la conducen a la dominación de las aguas solitarias e infinitas. La ambición de domeñarlas para llegar a nuevas tierras, está en el ambiente, aun no se ha navegado por la Mar Tenebrosa, aun no se ha descubierto nada, aun no se ha sometido nada, $y$ ya fray Hernando de Talavera, propone a Isabel la Católica, una gramática en lengua romance para sus nuevos súbditos; y también el romance intuye y presiente, la inquietud de avtenturar y el ansia de arrancar a la Mar Océana sus innúmeros secretos que sólo dirá, a quien por ella se atreva a navegar :

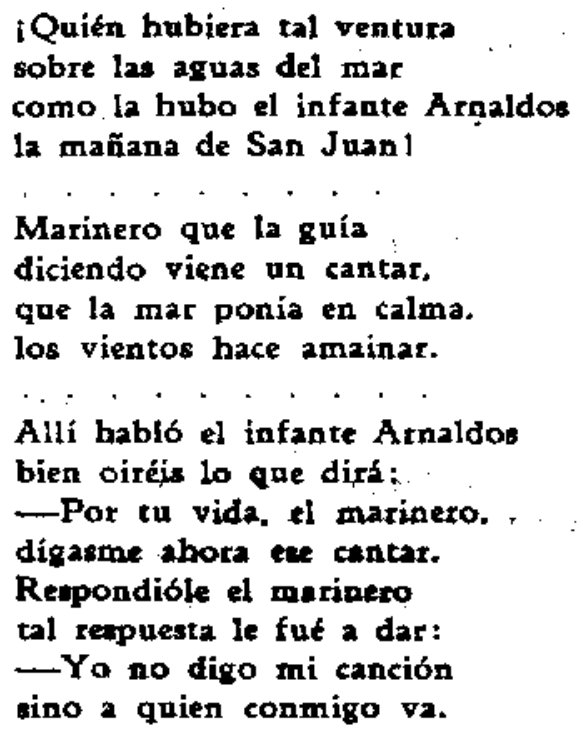

A Cristóbal Colón, el aqua en canto singular, reveló las rutas hacia un Nuevo Mundo de evasión. Y siguiendo al infante Arnaldos, una luminosa mañana de San Juan, el cansino Ponce de León, en busca de las aguas maravillosłas que devueliven la perdida juventud, descubrió las feraces tierras de la Florida.

Agua y viento, viento y agua, armónicamente conducen a los bajeles españoles a feliz término en sus arriesgados viajes. Día por día aumentan 
los iafantes afanosos de aventuras; y es Hernán Cortés, el predestinado a la gloria $y$ vencer a los elementos:

$$
\begin{aligned}
& \text { Rompe el mar, vence los vientos: } \\
& \text { llegando hasta donde no pudo } \\
& \text { con alas ilegar la fama... }
\end{aligned}
$$

Durante los azarosos días de lucha por el Imperio Azteca, los indios sometidos al Conquistador, en su expresión estética favorita -la danzaprincipiaron a manifestar las impresiones de su derrota. En la Danza de la Malinch̆e o de La Conquista de México que hasta nosotros llega, existen versos de indudable tonalidad romancesca, que aluden al fuerte poder del viento $y$ del fuego en el énfasis heroico:

\section{Moctezuma:}

Cuando el tiempo of tezca todo el tiempo nos alienta que cuidado se me da de que el viento se enfurezca.

$$
\text { Rey } 1^{\circ}
$$

Los vientos enfurecidos contraminando el valor son anuncioi de este dia en penoso tormento.

\section{Moctezuma :}

Quédese luego en el fuego ese valor que se eapera que el valor de mis vasallos se ha de sujetat la tierra.

\section{Rey $2^{9}$}

El fuego que nos anima $y$ el valor que nos alienta como se tira al morir. bace que el valor fallezca.

Cón la dominación de los caminos en las aguas abismales, y con la conquista de pródigos reinos, la riqueza es patrimonio hispano; pero con elta se tiene:

obligación de guardalla... 
y en las aguas verdosas del Atlántico, on las azules del Mediterráneo y en las plúmbeas del Septentrión, se columbran acechanzas de muerte. Las galeras francesas, las inglesas y las holandesas, aguardan a los galeones españoles para despojarlos. $Y$ son las carenas turquesas al mando de Dragut, las que no sólo pretenden el botín sino también la postración de la Cristiandad, y cuando el cristiano cae prisionero del infiel, clama al agua y a la tierra, pidiendo nuevas de su esposa y respuesta a sus preguntas:
Darne, pues. sagrado mas,
a mi demanda respuesta. si cual dicen es verdad que las aguas tienen lenguas.
En esto et descubrieton de 1 religín reis velas. Y el cómitre manda usar al forzado de an fuerza...

En las aguas mediterräneas se coaliga la Cristiandad para exterminar al turco, el romance Describese la batalla naval de Lepanto, ganada por don Juan de Austria a los titrcos, de cuya arriada solo se satva el ochalt Rey de Argel, con algunas galeras, nos dice cómo el viento, por intervención divina, se torna favorable a los cristianos:

$$
\begin{aligned}
& \text { Descubrieron el armada } \\
& \text { que próspeto viento traia, } \\
& \text { más Dios como es piadoso, } \\
& \text { a los suyos aunca olvida: } \\
& \text { por se gran micericordia. } \\
& \text { la mar calma laego hacia. } \\
& \text { El fuego iba y venia: } \\
& \text { no parece sino infiemo } \\
& \text { según el estruendo habia. } \\
& \text { Los unos decian: I Austria! } \\
& \text { otros decian: I Turquial. . }
\end{aligned}
$$

En esta batalla, el fuego, el agua salobre y el viento marino fueron instrumentos dóciles de los hispanos y será la última ocasión que suceda; en las' aguas nórdicas el fracaso del Imperio envidiado adviene definitivo.

El rey Felipe II, impulsado por excesivo celo religioso, envía su Armada Invencible contra los heréticos y los "vientos contrarios" y el agua en gigantescos tumbos combatieron furiosamente a la escuadra del rey de España y de Indias, que con razón culpó al agua y al viento del mal éxito en la cruzada. 
Con ta maerte del tey Felipe a cuyo duelo deben sumarise los elementos:

\author{
Todos cuatro elementos \\ pelean a mass porfia: \\ aire, fuego, tierra $\$$ agdra \\ hagen vefial de agonia...
}

y con la derrota de la Invencible, han terminado la era del agua, la era del viento y la era poderosa del poderoso Imperio Español.

Unos años antes del reinado de Felipe II, se alzó terrible el fuego, sus múrices llamas iluminaron el cielo de Europa y utilizado por los reformadores, redujo a cenizas al sabio Servet, al católico y a las brujas concurridoras sabatinas del aquelarre ; en Espenia, el fuego, instituido como en los denás paises desde la Edad Međia, fúé durante este período dique a la herejía, que casi no existió, puesto que el pueblo todo ebullia en exaltado odio al infiel; con los Reyes Católicos el fuego quemó judaizantes y con Fray Tomás de Torquemada al intensificarse la persecución de adeptos a la Reforma, el fuego obtiene su máximo poder.

Sin embargo, las grandes fogatas inquisitoriales no resplandecen on el Romancero; éste menciona al fuego conto sanción de amor, o cono castigo a infausto nuncio:
Mandó sin dilacion
el clérigo món metido
en una gronde hogruera
lo ha mandado quemar viro.
porque el sitompire cripó
que todo era fingido.

nunca por delitos al dogma. $Y$ es que el romance -metro y contenido popular- seguramente se identificó con las ideas politicas de la Inquisición; de lo contrario, hubiese recogido la tradición algún romance de los cantados a sovoz.

Y el más inbenso llameo, que destellará en el romance del siglo xIX, con teme de la época del César, tampoco está ligado a lo religioso, sino a una cuestión de honor; el fuego borra la afrenta que el Duque de Borbón infiere al Conde de Benavente:

\footnotetext{
"Y en cuanto él deje mi casa. antes que entrar yo en ella. purificaré con 'fuego sus paredes $y$ cus puertas', . .
} 
Desde aquella letal conjuración del agua y del viento, han transcurrido tres agónicos siglos para España; durante ellos, el hombre ha realizado su sueño —domeñar a los cuatro ingentes elementos-, tan poderosos que sólo la Verdad al decir del Cid, es capaz de resistir su embate:

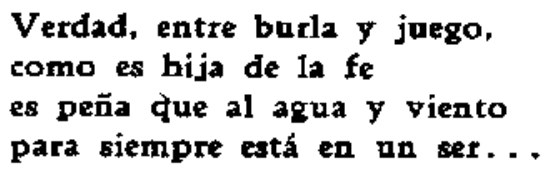

Cruzan ahora por el aire hispánico, gigantescas águilas que, arrojando fuego remedan a la que incendió la ciudad del conde don Grimaltos en el romance carolingio de Montesinos:

$$
\begin{aligned}
& \text { que vi un águila volar, } \\
& \text { siete balcones tras ella } \\
& \text { mal aquejándola van, } \\
& \text { y ella por guardarse de ellos } \\
& \text { retrajose a mi ciudad; } \\
& \text { encima de una alta torre } \\
& \text { alli se fuera asentar: } \\
& \text { por el pico echaba fuego, } \\
& \text { por las alas alquitrán; } \\
& \text { el fuego que de ella sale } \\
& \text { la ciudad bace quemar... }
\end{aligned}
$$

El romance de hoy -ínsito al trance heroico al igual que el arcaico- previene a la ciudad:

$$
\begin{aligned}
& \text { Rondan por tu cielo halcones } \\
& \text { que precipitarse quieren } \\
& \text { sobre tus rojos tejados. } \\
& \text { tus calles, tu brava gente... }
\end{aligned}
$$

Las desdichas por el aire volverán a llegar :

De presagios funerales el aire quieto se llena...

y entonces el romance anhela dolorosamente:

Aire, aire, aire, aire. si te pudiera cortar para que no entrase nadie... 
En el aire ya no luchan "las espadas de los lirios":

$$
\begin{aligned}
& \text { El aire conmovido } \\
& \text { por besos de lumbre } \$ \text { pena } \\
& \text { los disparos de fusil } \\
& \text { abren azucenas rojas... }
\end{aligned}
$$

EI aire está preñado:

$$
\begin{aligned}
& \text { El aire de azul caliente } \\
& \text { maduro de bayonetas... }
\end{aligned}
$$

El fuego sigue siendo exterminio:

$$
\begin{aligned}
& \text { Su fusil entre las manos } \\
& \text { era una rosa de fuego } \\
& \text { vomitando espanto } y \text { muerte } \\
& \text { para el enemigo negro... }
\end{aligned}
$$

y arde en el pecho del combatiente:

$$
\begin{aligned}
& \text { ¡Pronto, a las armas mi sangre. } \\
& \text { que ya me rebosa el fuegol }
\end{aligned}
$$

$Y$ al cesar los sufrimientos del soldado que cae, su cuerpo se desintegra en vivificantes elementos:

$$
\begin{aligned}
& \text { Vuélvete, daerme tranquilo, } \\
& \text { que aunque te vas, en España } \\
& \text { quedas hecho tierra y viento } \\
& \text { agua y luz viva del alba... }
\end{aligned}
$$

Actuales romances, con ideas de antiguos romances, nos hablan otra vez de las aguas del Tajo, de los "vientos contrarios", de las aguas del mar, que en la hora suprema aunan sus voces para exaltar el valor del héroe $y$ llorar su muerte:

¿Qué pena lleva el río Tajo. qué pena lleva hacia el mar!

En el mar los marineros blancou pañuelos le dan para que seque sus ojos. turbios de tanto llorar.

Los vientos son enemigos, 


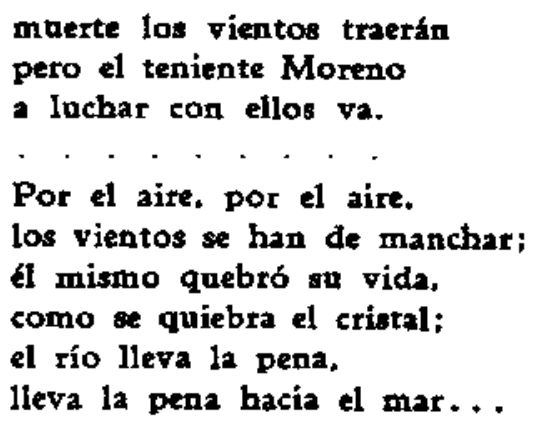

AZorin. El Paisaje de España visto por los españales. Col. Austral. Buenos Aitea, 1941. Dinz-Plaja, G. La Poesía lírica española. Col. Labor. Barcelona, 1937.

DUQUe de Rivas. Romances. Col. Apstral. Buenos Aires. 1938.

Floresta de leyendas heroicas españolas. Clásicos Castellanos. Madrid, 1926.

GARCix LORCA. FEDERICo. Romancero Gitano. Edit. Losada. Buenos Aires, 1943.

Machado, Antonio. Poesias completas. Edit. Losada. Buenos Aires, 1943.

Meléndez Valdés. Juan. Poesias. Clásicos Castellanos, Vol. 64. Madrid, 1925.

Ment́ndez Pidrl. R. La lengue de Cristóbal Colón. Col. Austral. Buenos Aires. 1942.

Rojas, Fernando DE. La Celestina. Edit. Sopena. Barcelona.

RojAs, Ricardo. Retablo Espanol. Edit. Losada. Buenos Aires, 1938.

Romancero Español. Edic. Aguilar. Madrid, 1930.

Romancero General. Vol. I y II. Edic. Rivadeneyra. Madrid, 1851.

Romancero General de la Guerta de España. Edic. españolas. Madrid-Valencia, 1937.

Spanish Texts of the three Dance Dramas from Mexican Villages. Published by University of Arizona. Tucson. Arizona, 1943. 